\title{
Diversity in the Axonal Transport of Structural Proteins: Major Differences Between Optic and Spinal Axons in the Rat
}

\author{
Irvine G. McQuarrie, ${ }^{*}$ Scott T. Brady, $\dagger^{+1}$ and Raymond J. Lasek $\dagger$ \\ *Division of Neurosurgery and *†Department of Developmental Genetics and Anatomy, School of Medicine, \\ Case Western Reserve University, Cleveland, Ohio 44106, and *Medical Research Service, Veterans \\ Administration Medical Center, Cleveland, Ohio 44106
}

Investigations of slow axonal transport reveal variation in both protein composition and the rate of movement. However, these studies involve a variety of nerve preparations in different species, and most lack the resolution needed to determine the kinetics of identified proteins. We have compared the axonal transport of slow-transported proteins in retinal ganglion cells and spinal motor neurons of young rats. Nine proteins that contribute to axonal structures were examined: the neurofilament triplet (NFT), alpha and beta tubulin, actin, fodrin, calmodulin, and clathrin. Axonally transported proteins were pulse-labeled by intraocular or intracord injections of ${ }^{35} S$-methionine. After allowing sufficient time for labeled slow-component proteins to enter the spinal or optic nerves, consecutive $2-3 \mathrm{~mm}$ nerve segments were subjected to SDS-PAGE. Fluorographs were used as templates for locating the gel regions containing the above polypeptides, and the radioactivity in these regions was measured by liquid-scintillation spectrometry.

In retinal ganglion cells, the peak of tubulin labeling advanced at $0.36 \mathrm{~mm} / \mathrm{d}$ in association with the NFT and fodrin. The cotransport of tubulin and the NFT identified this complex as the slower subcomponent of slow transport, termed slow component $a$ (SCa) and representing the movement of the microtubule-neurofilament network. The peaks of actin and calmodulin labeling were cotransported at $2.3 \mathrm{~mm} / \mathrm{d}$ in near-register with peaks of fodrin and clathrin labeling. These 4 proteins, moving ahead of the NFT, identified this complex as $\mathrm{SCb}$-the faster subcomponent of slow transport, which represents the movement of the cytoplasmic matrix and microtrabecular lattice. Both subcomponents had the same composition and rate as that reported for the optic axons of guinea pigs and rabbits, establishing a basic mammalian pattern.

In spinal motor axons, the $\mathrm{SCa}$ tubulin peak advanced at 1.3 $\mathrm{mm} / \mathrm{d}$, and the $\mathrm{SCb}$ actin and calmodulin peaks were cotransported at $3.1 \mathrm{~mm} / \mathrm{d}$. Unlike optic axons, $\mathrm{SCa}$ in motor axons was more heavily labeled than SC.b, and included labeled peaks of actin, clathrin, and calmodulin moving in register with the SCa tubulin peak. Actin was the most heavily labeled of these SCb proteins moving with SCa, and it left a higher plateau of

\footnotetext{
Received May 28, 1985; revised Dec. 9, 1985; accepted Dec. 18, 1985.
}

This work was supported by grants to I.G.M. from the Paralyzed Veterans of America (OVR-095), the Medical Research Service of the Veterans Administration, and the USPIIS (NS-18975); a grant to S.T.B. from the USPHS (NS-07118), and a program project grant to R.J.L. from the USPHS (NS-15731). We wish to thank Vivian Pocek, Magda Hadady, Shirley Ricketts, and Diane Filsinger for technical assistance; Nicholas Poolos and Edwin George for computer programs; Margaret Smith and Donald Schad for photography; and Marguarita Schmid for the line drawings.

Correspondence should be addressed to Dr. McQuarrie, Division of Neurosurgery, Case Western Reserve University School of Medicine, Cleveland, OH 44106.

Present address: Department of Cell Biology, University of Texas Health Science Center, Dallas, TX 75235.

Copyright $(c) 1986$ Society for Neuroscience $0270-6474 / 86 / 061593-13 \$ 02.00 / 0$ radioactivity behind the advancing SCa peak. The SDS-PAGE labeling pattern for SCb did not differ from that seen in optic axons, except that some tubulin was found to form a peak that advanced in register with the actin and calmodulin peaks. These observations demonstrate neuronotypic variation in the axonal transport of identified proteins moving with the slow component. Such differences may contribute to diversity in neuronal form and function.

In the decade since Hoffman and Lasek (1975) found that tubulin and the neurofilament proteins are conveyed through axons by the slow component (SC) of axonal transport, it has become apparent that SC represents the bulk movement of both the cytoplasmic matrix and the microtubule-neurofilament network (Lasek et al., 1984). All of the structural proteins of the axon (tubulin, actin, clathrin, fodrin, and the neurofilament triplet), as well as the proteins that regulate their polymerization (tau factors and calmodulin), are conveyed by SC (Lasek et al., 1984). The enzymes relating to glycolysis (neuron-specific enolase, creatine kinase, aldolase, pyruvate kinase, and lactic dehydrogenase) also move with SC. By contrast, proteins comprising membranous elements and enzymes relating to neurotransmission are conveyed by the fast component (Grafstein and Forman, 1980; Lasek et al., 1984).

$\mathrm{SC}$. has been examined in detail in the retinal ganglion cells of guinea pigs and rabbits, because newly synthesized proteins can be readily labeled by injecting radioactive amino acids into the vitreous humor of the eye. These studies demonstrate 2 subcomponents of SC, distinguished from each other by a 5- to 10-fold difference in transport rates and an almost completely different polypeptide composition. The slower subcomponent (SCa) conveys tubulin, tau factors, and the neurofilament triplet (NFT); $\mathrm{SCa}$ is thought to represent movement of the microtubule-neurofilament network (Black and Lasek, 1980; Mori and Kurokawa, 1980; Tytell et al., 1984). The faster subcomponent (SCb) carries actin, clathrin, calmodulin, myosin-like polypeptides, and the glycolytic enzymes (Black and Lasek, 1979; Brady and Lasek, 1981; Brady et al., 1981; Garner and Lasek, 1981; Mori and Kurokawa, 1981; Willard, 1977; Willard et al., 1979, 1980). Both subcomponents convey fodrin (Iasek et al., 1984; Levine and Willard, 1981), the neuronal form of spectrin (Lazarides and Nelson, 1983; Mangeat and Burridge, 1984). Biochemical evidence of specific interactions between each of the $\mathrm{SCb}$ proteins and one or more of the others is being reported with increasing frequency (e.g., Sobue et al., 1983; Westrin and Backman, 1983).

$\mathrm{SCb}$ is thought to represent movement of the microtrabecular lattice (MTL) and cytoplasmic matrix (Black and Lasek, 1979, 1980; Brady and Lasek, 1981; Ellisman and Porter, 1980; Hirokawa, 1982; Lasek et al., 1984). The concept of the MTL is more fully developed for non-neuronal cells, in which it appears 


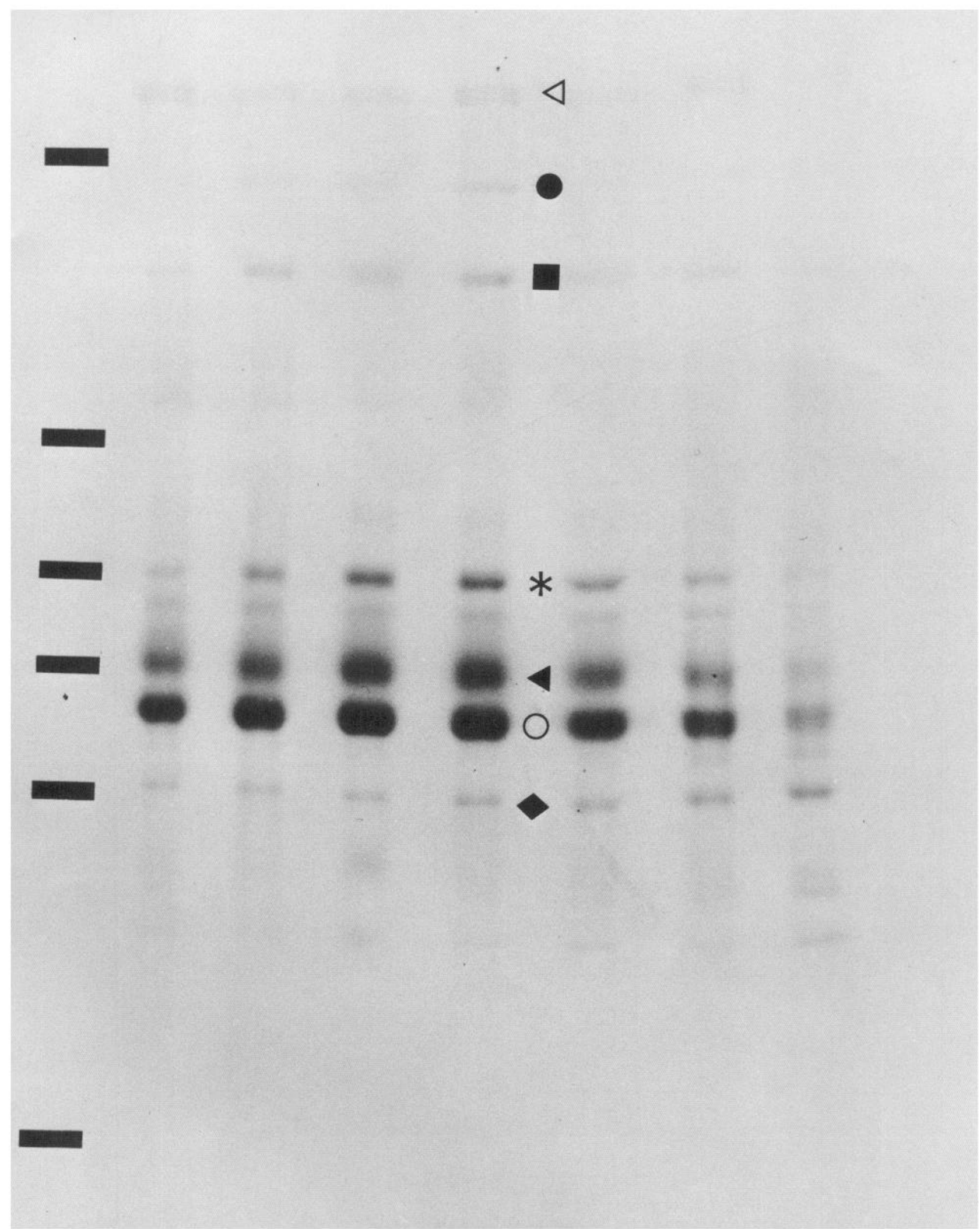

Figure 1. SDS-PAGE fluorograms showing labeled polypeptides in consecutive $2 \mathrm{~mm}$ segments of the right optic nerve and left optic tract $6 \mathrm{~d}$ (right) and $26 \mathrm{~d}(l e f t)$ after injection of $0.5 \mathrm{mCi}$ of ${ }^{35} \mathrm{~S}$-methionine into the right vitreous humor. Quantitative data obtained by using the left fluorogram as a template to remove gel regions containing tubulin and the NFT are shown in Figure 2; data obtained by using the right fluorogram to remove gel regions containing actin and calmodulin are shown in Figure 4. Left fluorogram was exposed for 2 weeks; right fluorogram for 1 


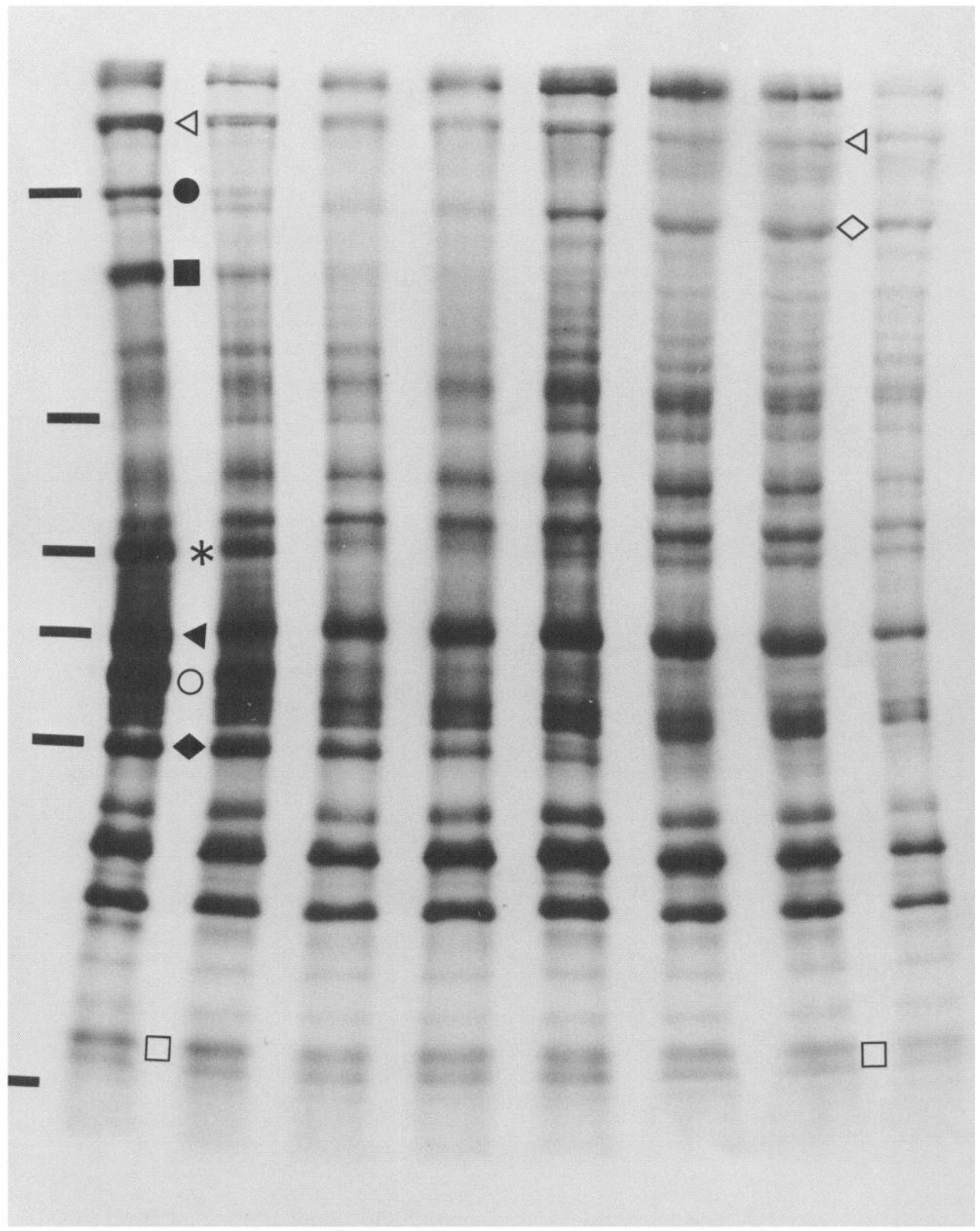

week. Bars indicate the positions of $M_{\mathrm{r}}$ standards $(200,94,68,57,43$, and $14 \mathrm{kDa}$, reading top to bottom). The polypeptides in this study are indicated by symbols: fodrin $(\triangleleft)$, neurofilament protein at $200 \mathrm{kDa}(\bullet)$, clathrin $(\diamond)$, NF protein at $145 \mathrm{kDa}(\square)$, NF protein at $68 \mathrm{kDa}(*)$, alpha tubulin $(\varangle)$, beta tubulin $(O)$, actin $(\diamond)$, and calmodulin $(\square)$. 


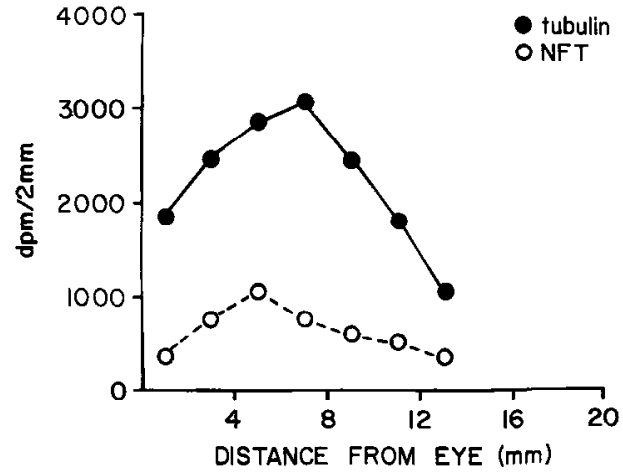

Figure 2. Transport of labeled tubulin and NFT proteins in optic axons at $26 \mathrm{~d}$ after intravitreal injection with $0.5 \mathrm{mCi}$ of ${ }^{35} S$-methionine (cf. Fig. 1, left). The position of the peak for total dpm of labeled proteins separated by $6-17.5 \%$ SDS-PAGE corresponded to the position of the labeled tubulin peak at $7 \mathrm{~mm}$ from the eye.

to organize the cytoplasmic matrix by loosely binding its myriad proteins (Hirokawa et al., 1983; Schliwa and van Blerkom, 1981; Schliwa et al., 1981; Wolosewick and Porter, 1979). Emerging evidence suggests that the MTL also plays that role in axons (Ellisman and Porter, 1980; Heriot et al., 1985; Hirokawa, 1982; Satir, 1984). Whether axons have a MTL that effectively constrains the movement of all matrix proteins is still a matter of debate (Gross et al., 1981; Lasek et al., 1984; Schnapp and Reese, 1982). However, experiments on non-neuronal cells in culture indicate that matrix constituents other than small metabolites are closely associated with the MTL (Satir, 1984; Schliwa and van Blerkom, 1981; Schliwa et al., 1981; Wojcieszyn et al., 1981).

Motor and sensory neurons of the rat sciatic nerve have been used to characterize the SC because their axons have sufficient length to demonstrate both $\mathrm{SCa}$ and $\mathrm{SCb}$ in a single nerve preparation (Hoffman and Lasek, 1975, 1980; Hoffman et al. 1983, 1984; Lasek, 1968; McQuarrie, 1983; McQuarrie et al., 1980; Mori et al., 1979; Oblinger et al., 1986; Tashiro and Komiya, 1983; Tashiro et al., 1984; Wujek and Lasek, 1983). Taken as a whole, these studies suggest several major differences from SC in the optic axons of guinea pigs and rabbits. Tubulin is conveyed by $\mathrm{SCb}$ as well as $\mathrm{SCa}$, and there is a prominent plateau of actin radioactivity trailing behind $\mathrm{SCb}$. In addition, there is more radioactivity in $\mathrm{SCa}$ than $\mathrm{SCb}$, and $\mathrm{SCa}$ advances much more rapidly than in optic axons. However, the transport kinetics of individual $\mathrm{SCa}$ and $\mathrm{SCb}$ proteins in rat spinal axons have not been examined quantitatively, nor has SC been characterized in rat optic axons. Should SC kinetics in rat optic axons conform to those seen in guinea pigs and rabbits, and should the emerging picture of SC kinetics in rat spinal axons be confirmed, a diversity of axonal cytoskeletal interactions would be implicit (Lasek et al. 1984; Tytell et al., 1981).

We have compared the axonal transport kinetics of structural proteins in optic and spinal axons of young adult rats. Retinal ganglion cells in other rodents (guinea pigs) show the most extreme separation of SCa and SCb in terms of kinetics and composition, while lumbar motor neurons of the rat appear to show the least separation. SDS-PAGE of consecutive 2-3 $\mathrm{mm}$ nerve segments was used to characterize the distribution of radioactivity in each structural or regulatory protein. This was supplemented by fluorography to obtain a template for removal of identified gel regions, these being analyzed by liquid-scintillation spectrometry. SC in optic axons was found to have the same characteristics as in guinea pigs and rabbits. Departures from this typical pattern were readily demonstrated in sciatic and obturator motor axons, confirming previous reports of tubulin moving with SCb (Hoffman and Lasek, 1980; McQuarrie,
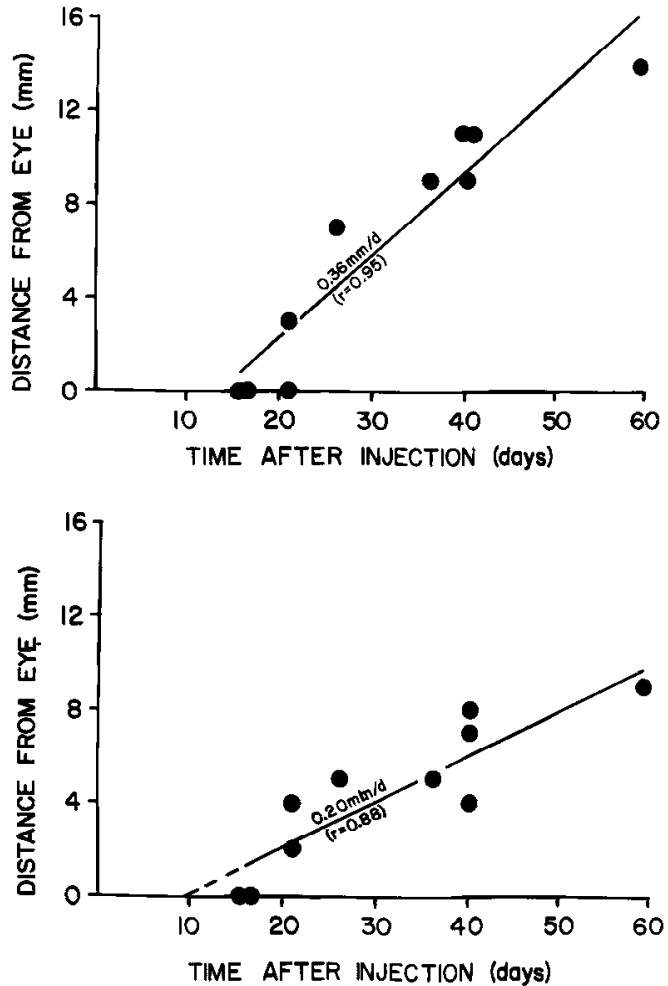

Figure 3. Positions of the labeled SCa tubulin peaks in 10 optic nerves at 16-59 d after intravitreal injection of $0.5 \mathrm{mCi}^{35} S$-methionine (top). Least-squares analysis of the regression of distance on time indicates a linear function $(p<0.001)$ with an estimated latency before the peak leaves the eye of $14 \mathrm{~d}$, and a translocation rate of $0.36 \pm 0.04 \mathrm{~mm} / \mathrm{d}$. Lower, The positions of the labeled NFT peaks in the same nerves. Least-squares analysis indicates a linear function $(p<0.001)$ with a latency of $9.2 \mathrm{~d}$ and a rate of $0.20 \pm 0.04 \mathrm{~mm} / \mathrm{d}$. The 2 regression functions are different $(p<0.02)$.

1983; McQuarrie et al., 1980; Mori et al., 1979; Oblinger et al., 1986; Tashiro and Komiya, 1983; Tashiro et al., 1984; Wujek and Lasek, 1983). In addition, the involvement of actin, calmodulin, and clathrin (proteins specific to $\mathrm{SCb}$ in optic axons) with SCa was found to be more extensive than any previous study had suggested. Labeled peaks of these proteins advanced through the axon in register with the peak of SCa tubulin labeling.

\section{Materials and Methods}

Male Sprague-Dawley rats (Zivic-Miller Laboratories) were used. For optic nerve studies, rats weighing $250-400 \mathrm{gm}$ had $0.5 \mathrm{mCi}$ of $\mathrm{L}-{ }^{35} \mathrm{~S}$ methionine injected into the right vitreous humor under ether anesthesia. The isotope was obtained from New England Nuclear at a specific activity of $0.5-1.0 \mathrm{mCi} / \mathrm{mm}$, lyophilized on arrival, and resuspended in distilled $\mathrm{H}_{2} \mathrm{O}(1-2 \mathrm{mCi} / 0.01 \mathrm{ml})$ immediately prior to injection. Rats were decapitated at 6-59 d after injection; the right optic nerves and contiguous left optic tracts were removed as a unit and frozen onto index cards in a straightened position. The frozen nerves were subsequently removed from the index cards, kept frozen under dry ice, and sectioned into consecutive $2 \mathrm{~mm}$ segments on a Mickle Gel Slicer (The Brinkman Instrument Co., Westbury, NY). The segments were homogenized (glass-to-glass) in $0.25 \mathrm{ml}$ of SUB: $0.5 \%$ SDS, $8 \mathrm{~m}$ urea, and $2 \%$ beta-mercaptoethanol. Homogenates were centrifuged at $20,000 \times$ $\mathrm{g}$ for $15 \mathrm{~min}$ at room temperature.

For spinal nerve studies, rats weighing 120-260 gm were anesthetized with intraperitoneal Chloropent (sodium pentobarbital and chloral hydrate; Fort Dodge Laboratories, Fort Dodge, IA) for removal of the $T-12, T-13$, and L-1 laminae to expose the spinal cord. Five injections of $0.1-0.2 \mathrm{mCi}$ of the above isotope solution were made in a parasagittal row into the motor columns serving the right $\mathrm{L}-3, \mathrm{~L}-4$, and $\mathrm{L}-5$ spinal nerves (Lasek, 1968; McQuarrie, 1978). An occasional animal developed evidence of hindlimb paresis following this procedure and was 


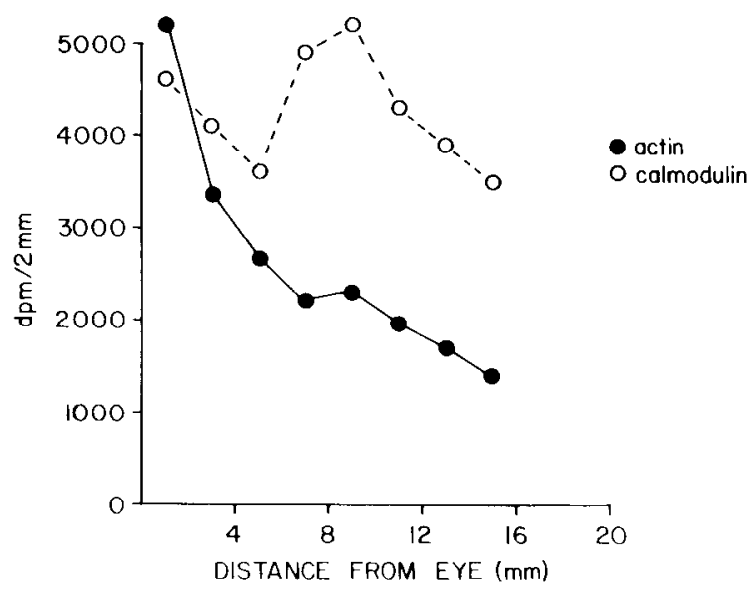

Figure 4. Transport of labeled actin and calmodulin in optic axons at $6 \mathrm{~d}$ after intravitreal injection of $0.5 \mathrm{mCi}$ with ${ }^{35} \mathrm{~S}$-methionine (cf. Fig. 1, right). Both proteins formed peaks of labeling at $9 \mathrm{~mm}$ from the eye.

eliminated from the study. Rats with normal neurological examinations were decapitated 4-41 d after injection. The contiguous ventral spinal roots and spinal nerves were removed such that the $L-4$ root/nerve was kept continuous with the sciatic nerve (formed mainly from the L-4 and L-5 spinal nerves), and the L-3 root/nerve was kept continuous with the obturator nerve (formed mainly from the L-3 spinal nerve). The L-5 root/nerve was cut at its juncture with L-4 to facilitate analysis; L-5 radioactivity levels were subsequently combined with those from L-4 to yield a distribution of radioactivity in the sciatic nerve. Each root/nerve preparation was straightened onto an index card and frozen; a piece of spinal cord marked the rostral extent of the ventral nerve root. The frozen nerves were sectioned into consecutive $3 \mathrm{~mm}$ segments, homogenized in SUB, and centrifuged as above.

The pellets were solubilized in $0.25 \mathrm{ml}$ BUST ( $2 \%$ beta-mercapto-

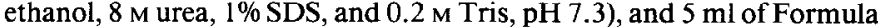
963 scintillation cocktail (New England Nuclear) was added. Radioactivity was measured in a liquid scintillation spectrometer (Beckman). A $10 \%$ aliquot of the supernatant was similarly analyzed for radioactivity. These measurements indicated that over $95 \%$ of the radioactivity in the homogenate of each nerve segment was in the supernatant. A 30$40 \%$ aliquot of the supernatant was subjected to SDS-PAGE, using a $4 \%$ stacking gel over a $4-17.5 \%$ or $6-17.5 \%$ gradient gel (Laemmli, 1970). Following electrophoresis, the gels were stained with $0.1 \% \mathrm{Coo}-$ massie brilliant blue in 35\% methanol and $7 \%$ acetic acid. Gels were destained for photography, following which they were impregnated with a fluor (2,5-diphenyloxazole) and vacuum-dried onto dialysis membranes in preparation for fluorography (Bonner and Laskey, 1974; Laskey and Mills, 1975).

Fluorograms were used as templates to remove gel regions that are known, from previously published identification studies (summarized by Lasek et al., 1984; Oblinger et al., 1986), to contain the neurofilament triplet, tubulins, actin, calmodulin, clathrin, and fodrin. Gel segments were solubilized in $0.5 \mathrm{ml}$ of $30 \% \mathrm{H}_{2} \mathrm{O}_{2}$ at $60^{\circ} \mathrm{C}$ for $2 \mathrm{~d}$; Formula 963 scintillation cocktail (New England Nuclear) or Ready-Solv HP/h (Reckman) was added, and radioactivity was measured in a liquid scintillation spectrometer (Beckman LS-335 or LS-6800, the latter equipped with a random coincidence monitor for detecting chemiluminescence). Radioactivity readings were corrected for background radiation, color quenching, isotopic decay, and counting efficiency; values were expressed as $\mathrm{dpm} / 2 \mathrm{~mm}$ (optic nerves) or $\mathrm{dpm} / 3 \mathrm{~mm}$ (spinal nerves).

For determining transport rates from the displacement of peaks of protein labeling, the least-squares method of calculating linear-regression functions was employed (Armitage, 1971). This allows Student's $t$ test to be used to determine if a linear function exists and provides the standard error of the slope. The significance of differences in slope can also be determined.

\section{Results}

\section{SCa in optic axons}

The leading foot of labeling for axonally transported tubulin entered the optic nerve at $6 \mathrm{~d}$ (Fig. 1, right), and the peak entered

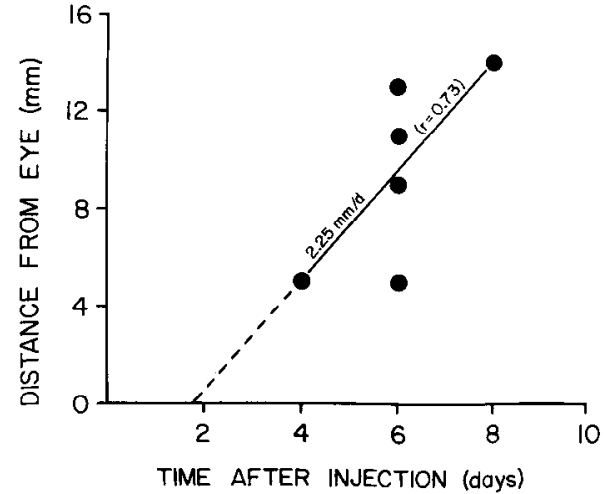

Figure 5. Position of the labeled $\mathrm{SCb}$ actin and calmodulin peaks in optic axons 4-8 d after intravitreal injection with $0.5 \mathrm{mCi}$ of ${ }^{35} S$-mcthionine $(n=6)$. In all 6 nerves, the actin and calmodulin peaks were found in the same $2 \mathrm{~mm}$ nerve segment. A least-squares analysis of the regression of distance on time suggests a linear function $(p<0.1)$ with an estimated latency before the peaks leave the eye of $1.8 \mathrm{~d}$ (dashed line) and a rate of $2.25 \pm 1.05 \mathrm{~mm} / \mathrm{d}$.

between 16 and $21 \mathrm{~d}$. By $26 \mathrm{~d}$ (Fig. 1, left), the tubulin peak had advanced several $\mathrm{mm}$ into the nerve and the peak for the less heavily labeled NFT had also entered the nerve (Fig. 2). The distance from the eye to the peak of tubulin labeling was measured in 10 nerves removed $16-59 \mathrm{~d}$ after injection: A leastsquares analysis of the regression of distance on time indicated that the peak advanced at $0.36 \pm 0.04 \mathrm{~mm} / \mathrm{d}$, after an estimated initial delay of $14 \mathrm{~d}$ (Fig. 3, top). In 4 of 10 nerves, the NFT peak was located in the same nerve segment as the tubulin peak. Least-squares analysis of the regression of distance to the NFT peak on time yielded a rate of $0.20 \pm 0.04 \mathrm{~mm} / \mathrm{d}$ after an estimated initial delay of $9.2 \mathrm{~d}$ (Fig. 3, lower). This rate was significantly slower than the SCa tubulin rate $(p<0.02)$.

In addition, the peak of overall SCa labeling was determined by totaling the $\mathrm{dpm} / 2 \mathrm{~mm}$ values for the 9 structural proteins examined in this study (or totaling the $\mathrm{dpm} / 2 \mathrm{~mm}$ for all proteins separated by SDS-PAGE). This gave the distribution of SCa labeling; the peak was found in the same $2 \mathrm{~mm}$ nerve segment as the peak of tubulin labeling in 9 of 10 nerves and

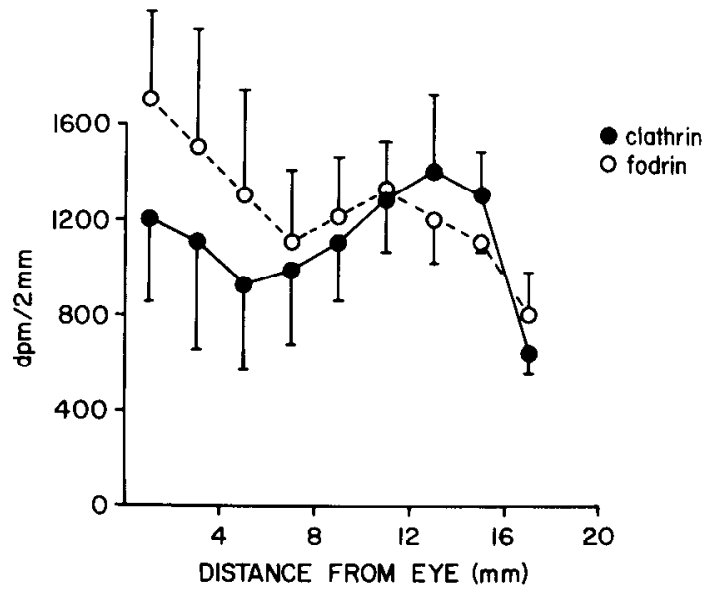

Figure 6. Transport of labeled clathrin and fodrin in optic axons $6 \mathrm{~d}$ after intravitreal injection with $0.5 \mathrm{mCi}$ of ${ }^{35} \mathrm{~S}$-methionine. A peak of labeling for clathrin was seen at $13 \mathrm{~mm}$ from the eye, and a fodrin peak at $11 \mathrm{~mm}$. The corresponding transport rates, assuming a $1 \mathrm{~d}$ delay before the peak entered the nerve (cf. Fig. 5), were 3.1 and $2.6 \mathrm{~mm} / \mathrm{d}$, respectively. Each point represents the mean \pm SEM of 3 nerves. For the individual nerves, clathrin peaks were located at 11,13 , and $15 \mathrm{~mm}$ from the eye; fodrin peaks were at 9,11 , and $13 \mathrm{~mm}$. 


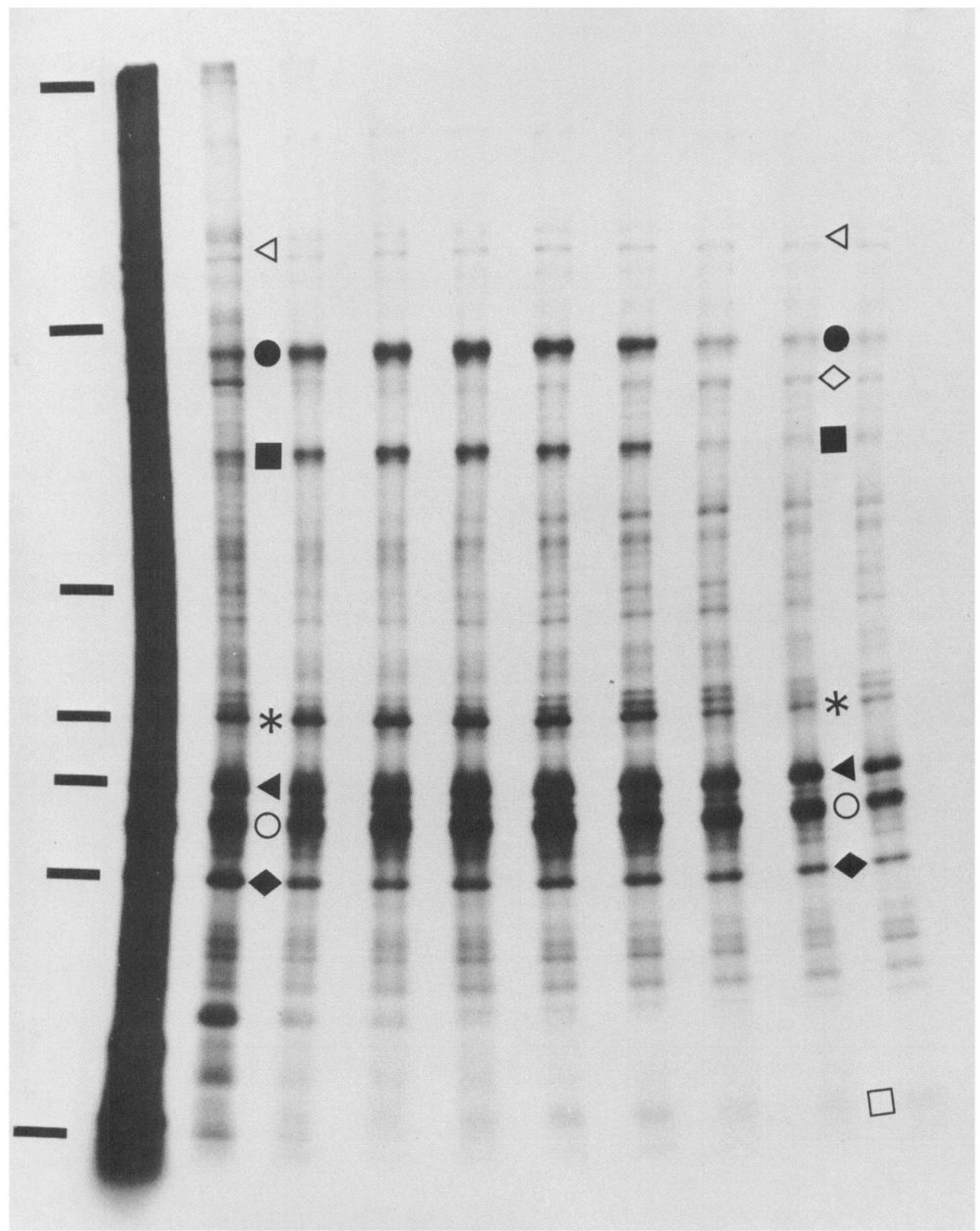

Figure 7. SDS-PAGE fluorograms showing labeled polypeptides in consecutive $3 \mathrm{~mm}$ segments of the L-3 ventral spinal root, L-3 spinal nerve, and obturator nerve $14 \mathrm{~d}$ after microinjection of the lumbar spinal cord with $0.65 \mathrm{mCi}$ of ${ }^{35} \mathrm{~S}$-methionine. Quantitative data obtained by using these fluorograms as templates to remove gel regions containing tubulin and the NFT are shown in Figure 8, and data obtained by removing gel regions containing actin and calmodulin in Figure 10. Left fluorogram (exposed for 2 weeks) shows heavily labeled spinal cord in lane 1, with the 


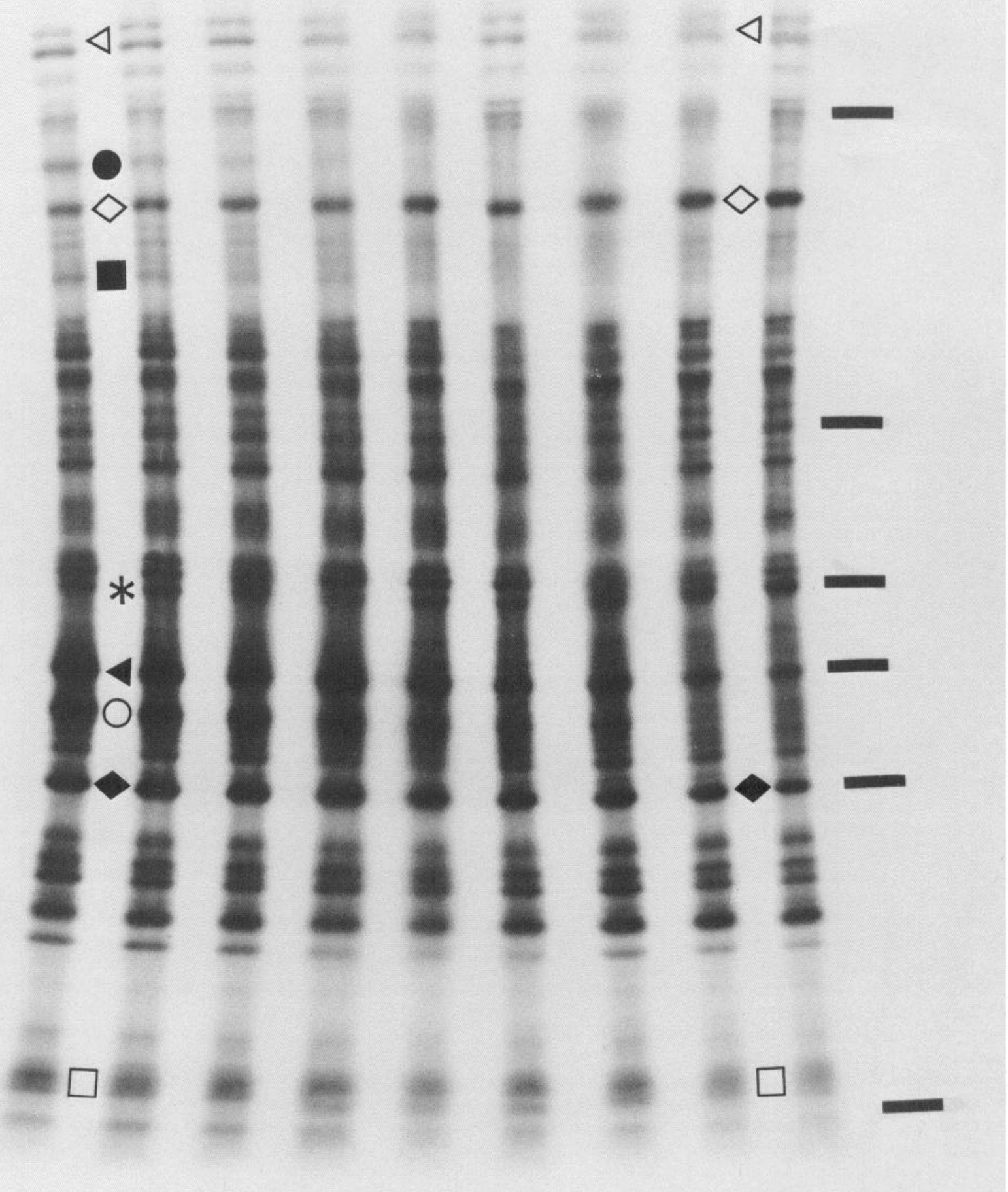

ventral nerve root beginning in lane 2; lanes 2-10 encompass nerve segments located 0-27 mm from the cord. Right fluorogram (exposed for 3 months) shows nerve segments located $27-54 \mathrm{~mm}$ from the cord. Bars in both parts of figure indicate the positions of $M_{\mathrm{r}}$ standards (400, 200, 94 , $68,57,43$, and $14 \mathrm{kDa}$, reading top to bottom). Polypeptides removed from the gel are indicated by symbols as in Figure 1 . 


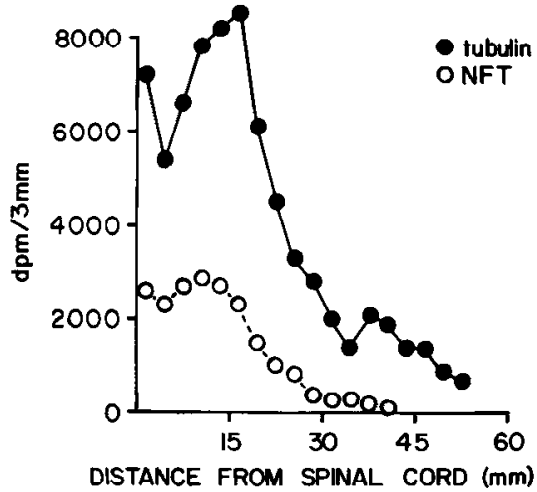

Figure 8. Transport of labeled tubulin and NFT proteins in obturator nerve motor axons $14 \mathrm{~d}$ after microinjection of the lumbar spinal cord in a rat weighing $215 \mathrm{gm}$. The fluorograms shown in Figure 7 were used to remove gel regions containing tubulin and the NFT in consecutive $3 \mathrm{~mm}$ nerve segments.

in an adjacent segment in the remaining nerve. Thus, the position of the SCa peak corresponded to the position of the tubulin peak, as opposed to the NFT peak. This is consistent with the observation that tubulin is more heavily labeled than the NFT in the rat optic nerve (e.g., Fig. 2).

Of the 3 traditional SCb proteins in this study-actin, calmodulin, and clathrin - only actin showed a tendency to form an SCa peak. A low plateau of actin radioactivity trailed behind the $\mathrm{SCb}$ actin peak, such that actin labeling was seen in SCa even after intervals of more than 3 weeks. (This plateau contained $25-50 \%$ of the radioactivity seen in the NFT.) In 4 of 6 such nerves, the plateau contained a shallow peak colocated with the SCa tubulin peak. In all but one of the 10 nerves, fodrin had a peak of SCa labeling. In each instance, this peak was located in the same segment as the SCa tubulin peak.

\section{$S C b$ in optic axons}

The peaks of labeling for actin and calmodulin had already entered the nerve by $4 \mathrm{~d}$ after injection, and by $6 \mathrm{~d}$ had moved several millimeters into the nerve (Fig. 4). In all 6 nerves removed 4-8 d after injection, the actin peak was in the same 2 $\mathrm{mm}$ nerve segment as the calmodulin peak. Least-squares analysis of the regression of distance to the actin/calmodulin peak on time indicated a rate of $2.25 \pm 1.05 \mathrm{~mm} / \mathrm{d}$, with an estimated initial delay of $1.8 \mathrm{~d}$ (Fig. 5). The less heavily labeled clathrin and fodrin peaks were found in the same nerve segment as the actin/calmodulin peaks (or in the adjacent segment) in 6 of 6 nerves. In addition, the peak of overall labeling ( $\mathrm{SCb}$ peak) was found in the same nerve segment as the actin/calmodulin peak in 6 of 6 nerves. SCb labeling exceeded SCa labeling.

Calmodulin was the most heavily labeled of the SCb proteins examined, followed by actin, clathrin, and fodrin. When the mean radioactivity levels for clathrin and fodrin were plotted at $6 \mathrm{~d}$ (to compensate for the low levels of clathrin and fodrin labeling by pooling data), clathrin was found to form a peak at $13 \mathrm{~mm}$ from the eye and fodrin a peak at $11 \mathrm{~mm}$ (Fig. 6). Assuming an initial delay of $1.8 \mathrm{~d}$ (Fig. 5), the corresponding transport rates were 3.1 and $2.6 \mathrm{~mm} / \mathrm{d}$, respectively.

\section{$S C a$ in spinal motor axons}

The peak of labeling for axonally transported SCa tubulin entered the lumbar spinal nerves between 4 and $7 \mathrm{~d}$ after pulselabeling the lumbar spinal cord with $0.5-1.2 \mathrm{mCi}$ of ${ }^{35} S$-methionine. By $14 \mathrm{~d}$, the peak had advanced approximately 15 $\mathrm{mm}$ - to the distal end of the spinal nerve roots (Figs. 7 and 8). The distance from the spinal cord to the peak of tubulin labeling
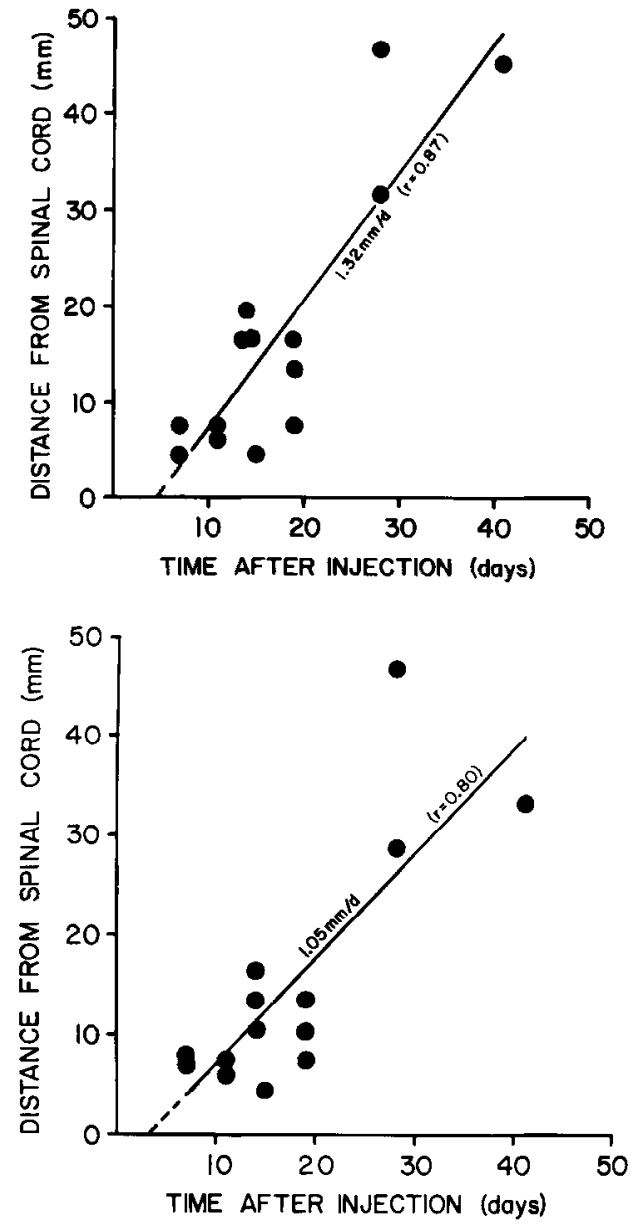

Figure 9. Top, Positions of the labeled SCa tubulin peaks in 14 sciatic and obturator nerve systems $7-41 \mathrm{~d}$ after microinjection of the lumbar spinal cord with $0.5-1.2 \mathrm{mCi}$ of ${ }^{35} S$-methionine. Least-squares analysis of the regression of distance on time indicates a linear function $(p<$ 0.001 ) with an estimated latency before the peak leaves the spinal cord of $4.5 \mathrm{~d}$ (dashed line) and a translocation rate of $1.32 \pm 0.21 \mathrm{~mm} / \mathrm{d}$. Lower, The positions of the labeled NFT peaks in the same nerves are shown. Least-squares analysis indicates a linear function $(p<0.001)$ with a latency of $3.1 \mathrm{~d}$ and a rate of $1.05 \pm 0.23 \mathrm{~mm} / \mathrm{d}$.

was measured in 18 nerves that were removed $7-41 \mathrm{~d}$ after labeling the spinal cord (Fig. 9, top). A least-squares analysis of the regression of distance on time indicated that the peak advanced at $1.32 \pm 0.21 \mathrm{~mm} / \mathrm{d}$, after an estimated initial delay of $4.5 \mathrm{~d}$. In 8 of the 14 nerves, the NFT peak was located in the same segment as the tubulin peak. Least-squares analysis of the regression of distance on time for the NFT peak yielded a rate of $1.05 \pm 0.23 \mathrm{~mm} / \mathrm{d}$, with an estimated initial delay of $3.1 \mathrm{~d}$ (Fig. 9, lower). Thus, the rate at which the tubulin peak advanced was almost 4-fold greater than in optic axons, and the rate for the NFT peak was more than 5-fold greater.

The overall SCa labeling was determined by totaling the $\mathrm{dpm} / 3$ $\mathrm{mm}$ in either the 9 structural/regulatory proteins or the total gel track. In 12 of 14 nerves, the SCa peak was in the same segment as the $\mathrm{SCa}$ tubulin peak. In the remaining 2 nerves, the SCa peak trailed 2 segments behind the tubulin peak. (One nerve had the SCa peak in the segment with the NFT peak, and the other had the SCa peak in the intervening segment.)

All of the traditional SCb proteins examined in this studyactin, calmodulin, and clathrin - formed peaks of labeling that moved with SCa, as did fodrin (Table 1). For example, an actin peak was located in the same segment as the tubulin peak, or 


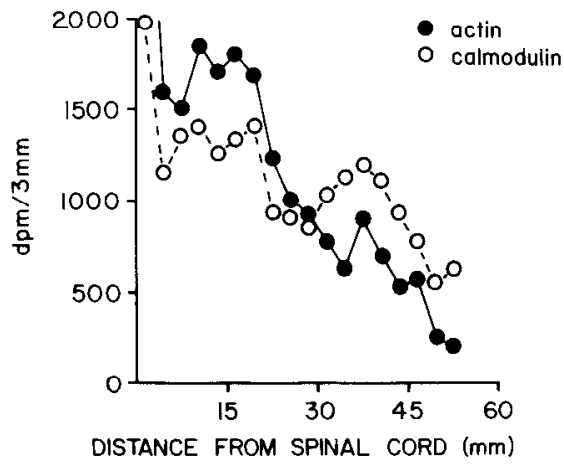

Figure 10. Transport of labeled actin and calmodulin in obturator nerve motor axons $14 \mathrm{~d}$ after microinjection of the lumbar spinal cord with $0.65 \mathrm{mCi}$ of ${ }^{3} \mathrm{~S} S$-methionine (same nerve as in Fig. 8). The fluorograms shown in Figure 7 were used as templates to remove selected gel bands representing labeled proteins in consecutive nerve segments. Actin and calmodulin formed 2 superimposed peaks of labeling: one centered at $15 \mathrm{~mm}$ from the cord (corresponding to the SCa wave of labeling) and $37.5 \mathrm{~mm}$ from the cord (marking the SCb wave). Note that labeled tubulin also forms a secondary peak at the latter position (Fig. 8).

in an immediately adjacent segment, in 12 of the 14 nerves used to assess $\mathrm{SCa}$.

\section{SCb in spinal motor axons}

Important differences from the $\mathrm{SCb}$ pattern in optic axons were consistently observed in spinal axons. The wave of SCb labeling appeared as a leading shoulder on the more heavily labeled $\mathrm{SCa}$ wave; this difference from the pattern in optic axons was due to the faster SCa rate and the larger amounts of transported tubulin and NFT in spinal motor axons. Since the rate of $\mathrm{SCb}$ in these axons was only $2-3 \times$ faster than the rate of $\mathrm{SCa}$, it was difficult to make a distinction between $\mathrm{SCb}$ and $\mathrm{SCa}$ from total radioactivity after injection intervals shorter than $5 \mathrm{~d}$. On the other hand, this facilitated analysis because intervals of 7-14 d captured both $\mathrm{SCa}$ and $\mathrm{SCb}$ in the same nerve (see Fig. 7). Most important, a long-term association of actin, calmodulin, and clathrin with $\mathrm{SCa}$ - and a long-term association of tubulin with $\mathrm{SCb}-$ was readily observed.

Even though it was difficult to define an overall wave of $\mathrm{SCb}$ labeling, calmodulin and clathrin consistently showed a wavefront or peak separate from SCa (Fig. 10). Most of the labeled actin traveled in association with $\mathrm{SCa}$ tubulin (Table 1); the $\mathrm{SCb}$ actin peak therefore appeared at the leading edge of the $\mathrm{SCa}$ actin wave (Fig. 10). At injection intervals shorter than $7 \mathrm{~d}$, the $\mathrm{SCb}$ actin peak was largely buried in the $\mathrm{SCa}$ actin wave. Nonetheless, 7 of the 10 nerves removed 5-14 d after injection had resolved an $\mathrm{SCb}$ actin peak; in 6 of these it was in the same segment as the $\mathrm{SCb}$ calmodulin peak, and in the seventh it was

Table 1. Actin, calmodulin, clathrin, and fodrin SCa peaks in spinal nerves

\begin{tabular}{|c|c|c|c|c|c|}
\hline Protein & $\begin{array}{l}\text { SCa tubu- } \\
\text { lin peak }\end{array}$ & $\Lambda$ djacent ${ }^{\alpha}$ & Other $^{a}$ & No peak & Total \\
\hline Actin & 9 & 3 & 0 & 2 & 14 \\
\hline Calmodulin & 7 & 4 & 1 & 2 & 14 \\
\hline Clathrin & 10 & 2 & 0 & 2 & 14 \\
\hline Fodrin & 10 & 3 & 0 & 1 & 14 \\
\hline
\end{tabular}

Fourteen spinal nerves evaluated 7-41 d after intracord injection of radiolabeled methionine (same nerves as in Fig. 9).

a Adjacent $=$ peak in nerve segment adjacent to $\mathrm{SCa}$ tubulin peak; other = peak more than one segment away from SCa tubulin peak.

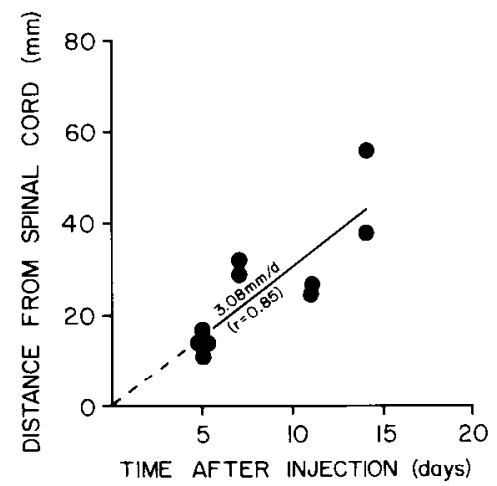

Figure 11. Position of labeled SCb actin and calmodulin peaks in sciatic and obturator nerve motor axons 5-14 d after microinjection of the lumbar spinal cord with $0.5-1.0 \mathrm{mCi}$ of ${ }^{35} S$-methionine $(n=10)$. Least-squares analysis of the regression of distance on time indicates a lincar function $(p<0.01)$ with an estimated latency of $0 \mathrm{~d}$ (dashed line) and a translocation rate of $3.08 \pm 0.69 \mathrm{~mm} / \mathrm{d}$. In 6 of 10 nerves, the actin and calmodulin peaks were found in the same segment; in one nerve, they were in adjacent segments and a mean distance was plotted. The remaining 3 nerves did not have a distinct $\mathrm{SCb}$ actin peak because of heavy SCa actin labeling, and the distance to the calmodulin peak was plotted.

in an adjacent segment. In addition, the tubulin moving with $\mathrm{SCb}$ formed a separate peak of labeling in most nerves removed during the second week after injection. In 5 of 6 such nerves, there was a discrete $\mathrm{SCb}$ tubulin peak; in 4 of these it was in the same segment as the SCb calmodulin peak ( $c f$. Figs. 8 and 10 ), and in the fifth it was in an adjacent segment bearing the $\mathrm{SCb}$ actin peak. As in optic axons, actin and calmodulin appeared to define a moving complex; in spinal motor axons this complex advanced at $3.08 \pm 0.69 \mathrm{~mm} / \mathrm{d}$ (Fig. 11).

Tubulin was the most heavily labeled protein moving with $\mathrm{SCb}$, followed by calmodulin, actin, clathrin, and fodrin. Clathrin and fodrin peaks were found in the same segment as the calmodulin peak in 5 of the 10 nerves, and in an adjacent seg-

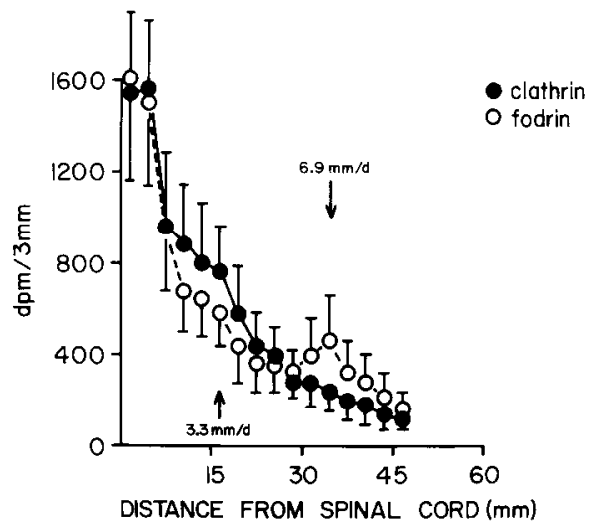

Figure 12. Transport of labeled clathrin and fodrin in sciatic and obturator nerve motor axons $5 \mathrm{~d}$ after microinjection of the lumbar spinal cord with $0.5-0.6 \mathrm{mCi}$ of ${ }^{35} S$-methionine. At $16.5 \mathrm{~mm}$ from the cord, a crest of labeling for both clathrin and fodrin is separating from SCa. The corresponding transport rate for this crest is $3.3 \mathrm{~mm} / \mathrm{d}$, assuming a negligible latency (cf. Fig. 11). The leading foot of $\mathrm{SCb}$ fodrin and clathrin labeling shows substantial radioactivity at least to $27 \mathrm{~mm}$, indicating that the maximum $\mathrm{SCb}$ rate is $5-6 \mathrm{~mm} / \mathrm{d}$. Each point represents the mean \pm SEM of 4 nerves. Note that labeled fodrin has a second peak at $34.5 \mathrm{~mm}$ from the cord, indicating a transport rate of $6.9 \mathrm{~mm} / \mathrm{d}$. This represents fodrin moving with group III of axonal transport (Levine and Willard, 1983). All 4 nerves had clathrin peaks, located $13.5,13.5,16.5$, and $19.5 \mathrm{~mm}$ from the cord; 3 nerves had fodrin peaks, located $13.5,16.5$, and $19.5 \mathrm{~mm}$ from the cord. 
Table 2. Characteristics of the slow component

\begin{tabular}{llllll} 
& \multicolumn{3}{l}{ Optic axons } & & \multicolumn{2}{l}{ Spinal axons } \\
\cline { 2 - 3 } \cline { 5 - 6 } \cline { 5 - 6 } & SCa & SCb & & SCa & SCb \\
\hline Rate & $0.36 \mathrm{~mm} / \mathrm{d}$ & $2.3 \mathrm{~mm} / \mathrm{d}$ & & $1.3 \mathrm{~mm} / \mathrm{d}$ & $3.1 \mathrm{~mm} / \mathrm{d}$ \\
Primary labeling & - & + & + & - \\
Composition & & & & & \\
NFT & + & - & + & - \\
Tubulin & + & - & + & + \\
Actin & $+/-$ & + & + & + \\
Calmodulin & - & + & + & + \\
Clathrin & - & + & + & + \\
Fodrin & + & + & + & +
\end{tabular}

ment in the remainder. When the mean radioactivity levels for clathrin and fodrin were plotted at $5 \mathrm{~d}$, the clathrin and fodrin peaks both appeared as a leading crest (separating from the $\mathrm{SCa}$ clathrin and fodrin waves) at $16.5 \mathrm{~mm}$ from the spinal cord (Fig. 12). Assuming a negligible initial delay (Fig. 11), the transport rate for these peaks was $3.3 \mathrm{~mm} / \mathrm{d}$.

A small leading foot of NFT labeling, evident on fluorograms and in gel punches, extended as far as the actin/calmodulin peak in 9 of the 10 nerves used to evaluate $\mathrm{SCb}$ (compare Figs. 8 and 10) - and as far as the clathrin/fodrin peak in 8 of 10 nerves. This leading foot had low levels of radioactivity in comparison to the NFT peak, and it seldom extended beyond the nerve segments containing the $\mathrm{SCb}$ peaks of actin, calmodulin, clathrin, and fodrin.

\section{Discussion}

This report describes the kinetics of movement for a set of identified polypeptides separated by SDS-PAGE on the basis of differences in $M_{\mathrm{r}}$. The use of fluorograms as a template for punching out gel regions containing polypeptides within a narrow $M_{\mathrm{r}}$ range gives consistent and reproducible results. However, any labeled polypeptide having an $M_{\mathrm{r}}$ within that range will contribute to the level of radioactivity ultimately measured for that gel scgment.

Identified proteins that contribute to axonal polymers and are resolvable by SDS-PAGE were examined. In support of this approach, we have carried out a study of $\mathrm{SCa}$ and $\mathrm{SCb}$ in optic and spinal axons using two-dimensional (2D) PAGE (Oblinger et al., 1986). In that study, polypeptides are separated on the basis of differences in isoelectric point (pI) before being subjected to SDS-PAGE; fluorograms show spots that locate individual labeled polypeptides, rather than bands that locate all labeled polypeptides having a particular $M_{\mathrm{r}}$. Thus, while it is unwieldly to use 2D-PAGE to measure radioactivity levels for individual polypeptides in consecutive nerve segments, we have used it to characterize labeled polypeptides in the peaks of $\mathrm{SCa}$ and $\mathrm{SCb}$ (Oblinger et al., 1986). These studies show that fodrin, actin, and the 2 higher $M_{\mathrm{r}}$ NFT proteins have little competition from labeled polypeptides at a similar $M_{\mathrm{r}}$. There are labeled polypeptides of unknown identity at the same $M_{\mathrm{r}}$ values as tubulin and the $68 \mathrm{kDa}$ NFT polypeptide. However, tubulin has 10-to 100-fold more radioactivity than its competing species, and the NFT polypeptide moves in a different rate-component of axonal transport from its competing species.

Clathrin is a long series of spots on 2D-PAGE, and calmodulin is more acidic than the standard $\mathrm{pI}$ range used for isoelectric focusing gels. Nonetheless, it is clear that there are no labeled species with $M_{\mathrm{r}}$ values close to clathrin's $(175 \mathrm{kDa})$, but there are competing labeled polypeptides within the variable (17-23 kDa) $M_{\mathrm{r}}$ range for calmodulin. On 2D-PAGE fluorograms, pre- pared with ampholines that resolve both calmodulin and the competing species, it is evident that the latter are weakly labeled, whereas calmodulin is strongly labeled (Brady and Lasek, 1981; Brady et al., 1981). Thus, the prominent pair of bands at $17-$ $23 \mathrm{kDa}$ on SDS-PAGE is considered to represent calmodulin.

\section{General characteristics of the slow component}

For SCa in optic axons, the fluorographic pattern in adult rats was the same as in guinea pigs and rabbits (Black and Lasek, 1980; Levine and Willard, 1980; Tytell et al., 1981, 1984; Willard and Hulebak, 1977; Willard and Simon, 1983). SCa appears to consist of the NFT proteins, tubulin, fodrin, microtubuleassociated proteins, and a trailing foot of $\mathrm{SCb}$ actin (Black and Lasek, 1980; Lasek et al., 1984; Oblinger et al., 1986; Tytell et al., 1984). We extended these observations by showing that fodrin and actin (in most cases) formed peaks of labeling that were cotransported with the peak of tubulin labeling (Table 2), whereas the NFT peak advanced more slowly (Fig. 3). The transport rate of the labeled SCa peak (corresponding to the position of the labeled tubulin peak) in rat optic axons was 0.36 $\mathrm{mm} / \mathrm{d}$, which is slightly faster than the rate of $0.25 \mathrm{~mm} / \mathrm{d}$ in the optic axons of guinea pigs (Black and Lasek, 1980). The rate of advance for the leading foot of SCa labeling is $0.7 \mathrm{~mm} / \mathrm{d}$ in rabbit optic axons and $0.5 \mathrm{~mm} / \mathrm{d}$ in guinea pig optic axons (Levine and Willard, 1980; Willard and Hulebak, 1977); the published fluorograms suggest that the labeled peaks move half as rapidly. Thus, the SCa rate in optic axons is essentially the same in these three species. We can conclude that the composition and kinetics of SCa in rat optic axons do not differ from the general pattern observed so far in mammalian optic nerves.

For $\mathrm{SCb}$ in rat optic axons, the fluorographic pattern of SDSPAGE gels was also similar to the published patterns for guinea pig and rabbit optic axons (Black and Lasek, 1979, 1980; Brady et al., 1981; Garner and Lasek, 1981, 1982; Levine and Willard, 1980, 1981; Tytell et al., 1981, 1984; Willard et al., 1979): Some 30-40 labeled bands were seen, including actin, fodrin, clathrin, calmodulin, neuron-specific enolase, and creatine kinase. A variety of methods have been used to establish the identity of these proteins, including comigration of labeled polypeptides with unlabeled polypeptides of known identity, peptide mapping, heat-denaturation studies, immunoblotting combined with immunostaining, and affinity chromatography (Black and Lasek, 1979; Brady and Lasek, 1981; Brady et al., 1981; Garner and Lasek, 1981; Levine and Willard, 1981; Willard et al., 1979).

The transport rate for the labeled $\mathrm{SCb}$ peak in rat optic axons, $2.3 \mathrm{~mm} / \mathrm{d}$, is consistent with the $2-3 \mathrm{~mm} / \mathrm{d}$ range found in guinea pig optic axons (Black and Lasek, 1979, 1980; Brady and Lasek, 1981; Brady et al., 1981; Garner and Lasek, 1982). It is clear that the optimum interval for capturing the $\mathrm{SCb}$ wave was the same as in the guinea pig: 6-9 d (Brady and Lasek, 1981; Brady et al., 1981). Our 2D-PAGE study of $\mathrm{SCb}$ in rat optic nerves now provides additional confirmation by showing that the peak is located 6-12 mm from the back of the eye after intervals of 6-7 d (Oblinger et al., 1986). The maximum rate for labeled $\mathrm{SCb}$ proteins is $3.4-4.3 \mathrm{~mm} / \mathrm{d}$ in rabbit optic axons, and $3-4 \mathrm{~mm} / \mathrm{d}$ in guinea pig optic axons (Levine and Willard, 1980; Willard and Simon, 1983; Willard et al., 1979); again, the published fluorograms suggest that the peaks of labeling advance half as rapidly. As in the case of $\mathrm{SCa}$, we can conclude that the composition and kinetics of $\mathrm{SCb}$ in rat optic axons conform to a general mammalian pattern.

Several studies have been made of the kinetics and composition of SCa in spinal motor axons of the rat, beginning with the original characterization of the NFT by Hoffman and Lasek (1975). In subsequent reports (Hoffman and Lasek, 1980; Hoffman et al., 1983), they have found that this SCa differs from the SCa in optic axons of rabbits and guinea pigs (Black and Lasek, 1980; Levine and Willard, 1980). These differences in- 
clude 2-5 $\times$ more labeling of SCa than SCb (the opposite relationship being found in optic axons) and an increase in the translocation rate for the peak of SCa labeling $(1.0-2.0 \mathrm{~mm} / \mathrm{d}$ in motor axons vs $0.2-0.3 \mathrm{~mm} / \mathrm{d}$ in optic axons). The present report confirms and extends these findings (Table 2 ) by measuring the translocation rates for the structural proteins of $\mathrm{SCa}$ and $\mathrm{SCb}$ in optic and spinal motor axons of young rats. New findings include the observation in motor axons that most of the actin moves with $\mathrm{SCa}$ tubulin and that tubulin also moves with $\mathrm{SCb}$ and is the most abundant $\mathrm{SCb}$ protein. In addition, calmodulin and clathrin are found to be transported with $\mathrm{SCa}$ as well as $\mathrm{SCb}$.

\section{Cytoskeletal interactions determine the kinetics of transport}

Some of the diversity we report can be related to the 10 -fold greater diameter of sciatic motor axons compared to optic axons (Forrester and Peters, 1967; Peyronnard and Charron, 1983): The greater amounts of NFT and tubulin transport correlate with the increase in axonal diameters and the corresponding increase in the numbers of microtubules and neurofilaments (Friede and Samorajski, 1970; Hoffman et al., 1984). However, there are additional differences between motor and optic axons that are not readily accounted for by differences in axonal diameter: a greater rate of $\mathrm{SCa}$, the presence of tubulin in $\mathrm{SCb}$, and the presence of actin, calmodulin, and clathrin in SCa. These differences appear to be related to the mechanics of slow transport and, specifically, to the detailed movements of cytoskeletal structures.

This interpretation follows from the structural hypothesis of axonal transport, which proposes that axonal proteins move because of their association with moving subcellular structures (Garner and Lasek, 1982; Heriot et al., 1985; Lasek et al., 1984; Tytell et al., 1981). To date, no other hypothesis accounts for 2 key facts: that the protein composition of each rate-component is essentially unique (Lasek et al., 1984; Tytell et al., 1981; Willard et al., 1974), and that each rate-component has sedimentation characteristics and protein markers that identify it (Black and Lasek, 1979, 1980; Brady and Lasek, 1981; Garner and Lasek, 1981, 1982; Heriot, 1981; Levine and Willard, 1980; Lorenz and Willard, 1978; Willard et al., 1979, 1980). Since the unique protein composition of each rate-component corresponds to a particular structure or structures, Lasek and his colleagues conclude that the protein kinetics are due to movement of the particular structures (Lasek et al., 1984; Tytell et al., 1981).

The structural hypothesis suggests that when 2 structures move at the same rate (e.g., microtubules and neurofilaments), they are interacting with each other (Black and Lasek, 1980; Hoffman and Lasek, 1975). If they were not interacting, their pulse-labeled proteins would still advance through the axon as a single wave of radioactivity. While it is possible that this could happen coincidentally, there is substantial evidence that it happens because of a physicochemical interaction between microtubules and neurofilaments. Ultrastructural studies demonstrate extensive crossbridging between these 2 structures in different types of axons; and the variety and specificity of the preparative methods indicate that crossbridges are real structures as opposed to artifacts of fixation (Ellisman and Porter, 1980; Hirokawa, 1982; Schnapp and Reese, 1982; Tsukita et al., 1982). Biochemical studies also suggest that microtubules readily associate with neurofilaments: When these 2 structures are combined in the presence of ATP, the viscosity is $5-20 \times$ greater than in the absence of any one ingredient (Runge et al., 1981). In an extension of these studies, Leterrier et al. (1984) have found that purified intact neurofilaments catalyze the formation of microtubules from pure tubulin. Finally, there is in vivo evidence for a physiological association between intermediate filaments and microtubules in non-neuronal cells, which can be demonstrated by using viral transformation to disrupt the association (Ball and Singer, 1981).

One motor may govern the movement of slowly transported fibrillar structures (Black and Lasek, 1979; Grafstein and Forman, 1980; Willard et al., 1979). This hypothesis is based on the presence of actin, myosin-like polypeptides, and glycolytic enzymes in $\mathrm{SCb}$, and has gained support from ultrastructural and biochemical evidence for interactions between the MTL, microtubules, and the axolemma (Brady and Lasek, 1981; Ellisman and Porter, 1980; Hirokawa, 1982; Lasek et al., 1984; McQuarrie, 1983; Willard, 1977). Since fodrin moves with both $\mathrm{SCa}$ and $\mathrm{SCb}$, and has a primarily subaxolemmal location, it is a candidate for the structural protein that links the MTL to both the axolemma and microtubules (Baitinger et al., 1983; Bennet et al., 1982; Heriot et al., 1985; Hirokawa, 1982; Hirokawa et al., 1983; Levine and Willard, 1981; Tytell et al., 1981). This is consistent with biochemical studies showing that axonal fodrin interacts with actin microfilaments and that erythrocytic fodrin (spectrin) serves to attach actin microfilaments to the cytoplasmic side of the plasma membrane (Cohen and Foley, 1980; Levine and Willard, 1981). In addition, there is ultrastructural and biochemical evidence that actin microfilaments can interact with microtubules (Griffith and Pollard, 1982). Thus, it is reasonable to propose that at least some of the structural proteins moving with $\mathrm{SCb}$ are capable of interacting with microtubules.

There is also biological evidence that the "motor" for transport of the axonal cytoskeleton is contained in $\mathrm{SCb}$, since the rate of regenerative axonal outgrowth approximates the $\mathrm{SCb}$ rate (Lasek et al., 1981; Wujek and Lasek, 1983), even when the rate of outgrowth is accelerated by using the "conditioning lesion" paradigm (McQuarrie, 1978, 1983, 1984; McQuarrie and Grafstein, 1982). If the motor for fibrillar structures moves with the $\mathrm{SCb}$ rate-component, it follows that these structures will move at rates that reflect the directness of their separate connections to the motor.

Some of the SC characteristics that differ between optic and spinal axons can be examined in light of the hypothesis that $\mathrm{SCb}$ is responsible for moving cytoskeletal structures. If this is true, then interactions between cytoskeletal structures will affect the transport rates for structural proteins. For example, comparison of the relative rates of $\mathrm{SCb}$ and $\mathrm{SCa}$ demonstrates that in motor axons SCa tubulin moves $58 \%$ slower than $\mathrm{SCb}$ actin, compared to $84 \%$ slower in optic axons, and additional SCb structural proteins (besides fodrin) move with $\mathrm{SCa}$ tubulin: clathrin and actin. These results suggest that microtubules in motor axons are more tightly connected to the MTL than in optic axons. Fodrin may be an essential link connecting the $\mathrm{SCb}$ motor to microtubules in $\mathrm{SCa}$, since peaks of labeled fodrin move in phase with peaks of both $\mathrm{SCa}$ tubulin and $\mathrm{SCb}$ actin in both optic and motor axons. In conclusion, we explain the neuronotypic differences that are related to the mechanism of slow transport by suggesting that $\mathrm{SCb}$ is responsible for the movement of microtubules. Thus, the rate of $\mathrm{SCa}$ is a function of the extent to which $\mathrm{SCb}$ structural proteins are able to interact with microtubules: the greater the interaction, the closer the $\mathrm{SCa}$ rate will be to the $\mathrm{SCb}$ rate.

\section{References}

Armitage, P. (1971) Statistical Methods in Medical Research, pp. 150163, 281-284, Wiley, New York.

Baitinger, C., R. Cheney, D. Clements, M. Glicksman, N. Hirokawa, J. Levine, K. Meiri, C. Simon, P. Skene, and M. Willard (1983) Axonally transported proteins in axon development, maintenance, and regeneration. Cold Spring Harbor Symp. Quant. Biol. 48: 791-802.

Ball, E. H., and S. J. Singer (1981) Association of microtubules and intermediate filaments in normal fibroblasts and its disruption upon 
transformation by a temperature-sensitive mutant of Rous sarcoma virus. Proc. Natl. Acad. Sci. USA 78: 6986-6990.

Bennet, V., J. Davis, and W. E. Fowler (1982) Brain spectrin: A membrane-associated protein related in structure and function to erythrocyte spectrin. Nature 299: 126-131.

Black, M. M., and R. J. Lasek (1979) Axonal transport of actin: Slow component $b$ is the principal source of actin for the axon. Brain Res. 171: 401-413.

Black, M. M., and R. J. Lasek (1980) Slow components of axonal transport: Two cytoskeletal networks. J. Cell Biol. 86: 616-623.

Bonner, W. M., and R. A. Laskey (1974) A film detection method for tritium-labeled proteins and nucleic acids in polyacrylamide gels. Eur. J. Biochem. 46: 83-88.

Brady, S. T., and R. J. Lasek (1981) Nerve-specific enolase and creatine phosphokinase in axonal transport: Soluble proteins and the axoplasmic matrix. Cell 23: 515-523.

Brady, S. T., M. Tytell, K. Heriot, and R. J. Lasek (1981) Axonal transport of calmodulin: A physiologic approach to identification of long-term associations between proteins. J. Cell Biol. 89: 607-614.

Cohen, C. M., and S. F. Foley (1980) Spectrin-dependent and -independent association of $\mathrm{F}$-actin with the erythrocyte membrane. J. Cell Biol. 86: 694-698.

Ellisman, M. H., and K. R. Porter (1980) Microtrabecular structure of the axoplasmic matrix: Visualization of cross-linking structures and their distribution. J. Cell Biol. 87: 464-479.

Forrester, J., and A. Peters (1967) Nerve fibers in optic nerve of rat. Nature 214: 245-247.

Friede, R. L., and T. Samorajski (1970) Axon caliber related to neurofilaments and microtubules in sciatic nerve fibers of rats and mice. Anat. Rec. 167: 379-388.

Garner, J. A., and R. J. Lasek (1981) Clathrin is axonally transported as a part of slow component b: The microfilament complex. J. Cell Biol. 88: 172-178.

Garner, J. A., and R. J. Lasek (1982) Cohesive transport of the slow component b complex of polypeptides. J. Neurosci. 2: 1824-1835.

Grafstein, B., and D. S. Forman (1980) Intracellular transport in neurons. Physiol. Rev. 60: 1167-1283.

Griffith, L. M., and T. D. Pollard (1982) The interaction of actin filaments with microtubules and microtubule-associated proteins. J. Biol. Chem. 257: 9143-9151.

Gross, G. W., G. H. Stewart, and B. Horowitz (1981) Molecular diffusion cannot account for spreading of isotope distribution peaks during rapid axoplasmic transport. Brain Res. 216: 215-218.

Heriot, K. (1981) Definition of the granulo-filamentous complex of the axon by biochemical and autoradiographic studies of the slow component $\mathrm{b}$ of axonal transport. Ph.D. dissertation, Case Western Reserve University, Cleveland, $\mathrm{OH}$.

Heriot, K., P. Gambetti, and R. J. Lasek (1985) Proteins transported in slow components $\mathrm{a}$ and $\mathrm{b}$ of axonal transport are distributed differently in the transverse plane of the axon. J. Cell Biol. 100: 11671172.

Hirokawa, N. (1982) Cross-linker system between neurofilaments, microtubules, and membranous organelles in frog axons revealed by the quick-freeze, deep-etching method. J. Cell Biol. 94: 129-142.

Hirokawa, N., R. E. Cheney, and M. Willard (1983) Location of a protein of the fodrin-spectrin-TW260/240 family in the mouse intestinal brush border. Cell 32: 953-965.

Hoffman, P. N., and R. J. Lasek (1975) The slow component of axonal transport. Identification of major structural polypeptides of the axon and their generality among mammalian neurons. J. Cell Biol. 66: 351-366.

Hoffman, P. N., and R. J. Lasek (1980) Axonal transport of the cytoskeleton in regenerating motor neurons: Constancy and change. Brain Res. 202: 317-333.

Hoffman, P. N., R. J. Lasek, J. W. Griffin, and D. L. Price (1983) Slowing of the axonal transport of neurofilament proteins during development. J. Neurosci. 3: 1694-1700.

Hoffman, P. N., J. W. Griffin, and D. L. Price (1984) Control of axonal caliber by neurofilament transport. J. Cell Biol. 99: 705-714.

Laemmli, U. K. (1970) Cleavage of structural proteins during the assembly of the head of bacteriophage T4. Nature 227: 680-685.

Lasek, R. J. (1968) Axoplasmic transport of labeled proteins in rat ventral motoneurons. Exp. Neurol. 21: 41-51.

Lasek, R. J., I. G. McQuarrie, and J. R. Wujek (1981) The central nervous system regeneration problem: Neuron and environment. In Posttraumatic Peripheral Nerve Regeneration, A. Gorio, H. Millesi, and S. Mingrino, eds., pp. 59-70, Raven, New York.
Lasek, R. J., J. A. Garner, and S. T. Brady (1984) Axonal transport of the cytoplasmic matrix. J. Cell Biol. 99: 212s-221s.

Laskey, R. A., and A. D. Mills (1975) Quantitative film detection of ${ }^{3} \mathrm{H}$ and ${ }^{14} \mathrm{C}$ in polyacrylamide gels by fluorography. Eur. J. Biochem. 56: 335-341.

Lazarides, E., and W. J. Nelson (1983) Erythrocyte and brain forms of spectrin in cerebellum: Distinct membrane-cytoskeletal domains in neurons. Science 220: 1295-1296.

Leterrier, J.-F., J. Wong, R. K. H. Liem, and M. L. Shelanski (1984) Promotion of microtubule assembly by neurofilament-associated microtubule-associated proteins. J. Neurochem. 43: 1385-1391.

Levine, J., and M. Willard (1980) The composition and organization of axonally transported proteins in the retinal ganglion cells of the guinea pig. Brain Res. 194: 137-154

Levine, J., and M. Willard (1981) Fodrin: Axonally transported polypeptides associated with internal periphery of many cells. J. Cell Biol 90: 631-643.

Lorenz, T., and M. Willard (1978) Subcellular fractionation of intraaxonally transported polypeptides in the rabbit visual system. Proc Natl. Acad. Sci. USA 75: 505-509.

Mangeat, P. H., and K. Burridge (1984) Immunoprecipitation of nonerythrocyte spectrin within live cells following microinjection of specific antibodies: Relation to cytoskeletal structures. J. Cell Biol. 98. 1363-1377.

McQuarrie, I. G. (1978) The effect of a conditioning lesion on the regeneration of motor axons. Brain Res. 152: 597-602.

McQuarric, I. G. (1983) Role of the axonal cytoskeleton in the regenerating nervous system. In Nerve, Organ, and Tisstue Regeneration: Research Perspectives, F. J. Seil, ed., pp. 51-88, Academic, New York.

McQuarrie, I. G. (1984) Effect of a conditioning lesion on axonal transport during regeneration: The role of slow transport. Adv. Neurochem. 6: 185-209.

McQuarrie, I. G., and B. Grafstein (1982) Protein synthesis and axonal transport in goldfish retinal ganglion cells during regeneration accelerated by a conditioning lesion. Brain Res. 251: 25-37.

McQuarrie, I. G., S. T. Brady, and R. J. Lasek (1980) Polypeptide composition and kinetics of $\mathrm{SCa}$ and $\mathrm{SCb}$ in sciatic motor axons and optic axons of the rat. Soc. Neurosci. Abstr. 6: 501.

Mori, H., and M. Kurokawa (1980) Morphological and biochemical characterization of neurofilaments isolated from the rat peripheral nerve. Biomed. Rcs. 1: 24-31.

Mori, H., and M. Kurokawa (1981) Intra-axonal transport of clathrin and actin. Biomed. Res. 2: 677-685.

Mori, H., Y. Komiya, and M. Kurokawa (1979) Slowly migrating axonal polypeptides. Inequalities in their rate and amount of transport between two branches of bifurcating axons. J. Cell Biol. 82: 174-184.

Oblinger, M. M., S. T. Brady, I. G. McQuarrie, and R. J. Lasek (in press) Differences in the protein composition of the axonally transported cytoskeleton in peripheral and central mammalian neurons. J. Neurosci.

Peyronnard, J. M., and L. Charron (1983) Motoneuronal and motor axonal innervation in the rat hindlimb: A comparative study using horseradish peroxidase. Exp. Brain Res. 50: 125-132.

Runge, M. S., T. M. Laue, D. A. Yphantis, M. R. Lifsics, A. Saito, M. Altin, K. Reinkc, and R. C. Williams, Jr. (1981) ATP-induced formation of an associated complex between microtubules and neurofilaments. Proc. Natl. Acad. Sci. USA 78: 1431-1435.

Satir, P. (1984) Cytoplasmic matrix: Old and new questions. J. Cell Biol. 99: 235s-238s.

Schliwa, M., and J. van Blerkom (1981) Structural interaction of cytoskeletal components. J. Cell Biol. 90: 222-235.

Schliwa, M., J. van Blerkom, and K. R. Porter (1981) Stabilization of the cytoplasmic ground substance in detergent-opened cells and a structural and biochemical analysis of its composition. Proc. Natl. Acad. Sci. USA 78: 4329-4333.

Schnapp, B. J., and T. S. Reese (1982) Cytoplasmic structure in rapidfrozen axons. J. Cell Biol. 94: 667-679.

Sobue, K., K. Kanda, J. Adachi, and S. Kakiuchi (1983) Calmodulinbinding proteins that interact with actin filaments in $\mathrm{C} \mathrm{Ca}^{2+}$-dependent flip-flop manner: Survey in brain and secretory tissues. Proc. Natl. Acad. Sci. USA 80: 6868-6871.

Tashiro, T., and Y. Komiya (1983) Two distinct components of tubulin transport in sensory axons of the rat recognized by dimethyl sulfoxide treatment. Biomed. Res. 4: 443-450.

Tashiro, T., M. Kurokawa, and Y. Komiya (1984) Two populations of axonally transported tubulin differentiated by their interactions with neurofilaments. J. Neurochem. 43: 1220-1225. 
Tsukita, S., J. Usukura, S. Tsukita, and H. Ishikawa (1982) The cytoskeleton in myelinated axons: A freeze-etch replica study. Neuroscience $7:$ :2135-2147.

Tytell, M., M. M. Black, J. A. Garner, and R. J. Lasek (1981) Axonal transport: Each major rate component reflects the movement of distinct macromolecular complexes. Science 214: 179-181.

Tytell, M., S. T. Brady, and R. J. Lasek (1984) Axonal transport of a subclass of $\{\tau\}$ proteins: Evidence for the regional differentiation of microtubules in neurons. Proc. Natl. Acad. Sci. USA 81: 1570-1574.

Westrin, H., and L. Backman (1983) Association of rabbit muscle glycolytic enzymes with filamentous actin. A countercurrent distribution study at high ionic strength. Eur. J. Biochem. 136: 407-411.

Willard, M. (1977) The identification of two intra-axonally transported polypeptides resembling myosin in some respects in the rabbit visual system. J. Cell Biol. 75: 1-11.

Willard, M., and K. L. Hulcbak (1977) The intra-axonal transport of polypeptide $\mathrm{H}$ : Evidence for a fifth (very slow) group of transported proteins in the retinal ganglion cells of the rabbit. Brain Res. 136: 289-306.

Willard, M., and C. Simon (1983) Modulations of neurofilament axonal transport during the development of rabbit retinal ganglion cells. Cell 35: 551-559.
Willard, M., W. M. Cowan, and P. R. Vagelos (1974) The polypeptide composition of intra-axonally transported proteins: Evidence for four transport velocities. Proc. Natl. Acad. Sci. USA 71: 2183-2187.

Willard, M., M. Wiseman, J. Levine, and P. Skene (1979) The axonal transport of actin in rabbit retinal ganglion cells. J. Cell Biol. 81:581591

Willard, M., C. Simon, C. Baitinger, J. Levine, and P. Skene (1980) Association of an axonally transported polypeptide $(\mathrm{H})$ with $100-$ Angstrom filaments. Use of immunoaffinity electron microscope grids. J. Cell Biol. 85: 587-596.

Wojcieszyn, J. W., R. A. Schlegel, E.-S. Wu, and K. A. Jacobson (1981) Diffusion of injected macromolecules within the cytoplasm of living cells. Proc. Natl. Acad. Sci. USA 78: 4407-4410.

Wolosewick, J. J., and K. R. Porter (1979) Microtrabecular lattice of the cytoplasmic ground substance. Artifact or reality? J. Cell Biol. 82 . 114-139.

Wujek, J. R., and R. J. Lasek (1983) Correlation of axonal regeneration and slow component $B$ in two branches of a single axon. J. Neurosci. 3: $243-251$. 